\title{
Psychiatric morbidities in patients with primary headache
}

\author{
Sanjeev Chandra Gautam ${ }^{1 *}$ iD, Yash Bhattarai ${ }^{\text {ID }}$, Pradip Man Singh ${ }^{3}$ \\ 'Lecturer, Department of Psychiatry, Nepal Medical College, Nepal. ${ }^{2}$ Medical Officer, Kapan Hospital. ${ }^{3}$ Associate Professor, \\ Department of Psychiatry, Nepal Medical College, Nepal.
}

\begin{abstract}
Background: Headache is a pain that occurs above the eyes or the ears, behind the head in the occiput or the cervical region of the neck. A primary headache is a type of headache that is caused by overactivity of, or the problems with pain-sensitive structures and is not a symptom of an underlying disease condition. This study highlights the association of Primary Headaches with psychiatric morbidities and stressful life events that may cause or increase its severity. Method: Descriptive, Cross-Sectional, Hospital Based study was done in 75 patients who met the diagnostic criteria for Primary Headache. Results: Patients presenting with primary headache were mostly from the age group of $26-30(26.7 \%)$. Most were female (57.3\%) and $69.3 \%$ were married. $29.3 \%$ of the patients were housewives, $25.3 \%$ were into service and $21.4 \%$ were students. Anxiety and depression were the major diagnosis with 22.3 and 17.4 $\%$ respectively. Illness in the family and self or family member unemployment were the major stressful life events. There was a significant relation of Psychiatric Morbidity with Primary Headache. Conclusion: Anxiety disorder was the major psychiatric condition found in patients with Primary Headache followed by depression. Majority of this was seen in females, married and in the age group of 26-30 years. Thus it is necessary to screen Primary Headaches and reduce the stressful life events in these patients and limit the consequences and outcome of Primary Headache to prosper the health and living standard of the patients and the population as a whole.
\end{abstract}

Keywords: General Health Questionnaire, ICD-10 DCR, Presumptive Stressful Life Event Scale, Primary Headache, Self Reporting Questionnaire

\section{Correspondence to:}

Dr. Sanjeev Chandra Gautam

Lecturer, Department of Psychiatry

Nepal Medical College, Nepal

E-mail: sanjeevchandragautam@gmail.com

Submitted: February 9, 2020

Accepted: June 26, 2020

To cite: Gautam SC, Bhattarai Y, Singh PM. Psychiatric morbidities in patients with primary headache. JGMC Nepal. 2020;13(2):122-7.

DOI: 10.3126/jgmcn.v13i2.27611

\section{INTRODUCTION}

Pain that occurs above the eyes or the ears, behind the head in the occiput or the cervical region of the neck can be called as a headache. Literatures on headache can be traced back to at least to the past 4000 years to Mesopotamian ritual texts, by which it can be observed that headache is one of the most common complaint of mankind. ${ }^{1}$ The pain is produced by the stimulation of skin, subcutaneous tissue, muscle, arteries and periosteum of skull and has minimum impact from brain as a whole including ependymoma and choroid plexus, as they are insensitive to pain. Headaches can be Primary or Secondary. A primary headache is a type of headache that is caused by overactivity of, or the problems with pain-sensitive structures in our head and is not a symptom of an underlying disease condition in a patient. The activities of chemicals in our brain, the nerves or vessels surrounding the skull or the muscles of our head and neck plays an important role and mainly includes Cluster type headaches, migraine, tension type headache and 
trigeminal autonomic cephalgia. Use of alcohol (particularly red wine), certain foods (eg: processed meats that contain nitrates), changes in sleep pattern, poor posture and stress can be some of the triggering factors of Primary Headache. Secondary Headaches are related to other biological disorders (eg: neoplasm, infection or toxin).

Tension Type Headache and Migraine are one of the most prevalent diseases in the world ranking second and third ${ }^{2}$ and are considered distinct entities by the International Headache Society. There is a two to three fold greater risk of having a psychiatric morbidity in patients with headache than general population ${ }^{3,4}$ and studies over 25 years have consistently indicated that headaches and anxiety and depression are excessively co-morbid. ${ }^{5-8}$ Headaches has also been found to severely affect the quality of life of the individual with exaggerated effects and disability. ${ }^{9-11}$ Epidemiological studies have been done and has shown a strong association between primary headaches and psychiatric disorders ${ }^{12}$ and the reported prevalence was about $66.1 \% \cdot{ }^{13,14}$ A study done in Italy compared anger and emotional distress in patients with migraine and tension type headache and showed higher level of angry temperament and anger among patients with tension type headache and in addition to this also showed high level of phobia, depression, anxiety, obsessive compulsive symptoms, emotional lability and other psychological disorders. ${ }^{15}$ The study of prevalence of psychiatric morbidities with headache in Nepal has been limited. A study conducted by Risal et al. ${ }^{16}$ showed high prevalence of both headache and psychiatric disorders, are excessively comorbid with anxiety and depression. Association with tension type headache and psychiatric comorbidity as per diagnosis of tension-type headache has been missed out while being diagnosed as per depression or anxiety as these disorders have headache as one of their symptoms. ${ }^{17}$ Another study has also showed that anxiety and depression as comorbid disorder among those presenting with Primary Headache in Nepal. ${ }^{18}$

Primary types of headaches are the most common types of problem reported in the OPD by the patients hence it is necessary for a proper study in this matter. The high prevalence of Primary Headache and its effects on work productivity, quality of life and socio-economic condition is a matter to be focused on. This study highlights on the association of Primary Headaches with psychiatric morbidities and stressful life events that may cause or increase the severity of Primary Headache and its psychiatric co-morbidities.

\section{OBJECTIVES}

The general objective of this study is to study the psychiatric morbidities in patients with Primary Headache. The specific objectives of this study is to study the prevalence and nature of psychiatric morbidity in patients diagnosed with Primary Headache, to study the relationship between stress of life and primary headache; and to study the socio-demographic profile and prevalence of Primary Headache.

\section{MATERIALS AND METHODOLOGY}

Study conducted at Department of Psychiatry, NMCTH, Jorpati, Gokarneshwor-8, Kathmandu, Nepal within a period of 1 year (1st November 2017- 31st October 2018). A descriptive, cross-sectional, hospital based study was done with a sample size of 75 people $(n=75)$. Sample selected according to the inclusion and exclusion criteria. The inclusion criteria included patients diagnosed with Primary Headache by a consultant psychiatrist and requiring the diagnosis of Primary Headache according to International Headache Society classification ${ }^{19}$ who gave informed consent to participate from any gender and age group of $>10$ years of age. Follow up cases, patients with comorbid medical illness, patients who did not give informed consent, patient who did not meet criteria for Primary Headache and patients suffering from other medical and surgical illness which are directly attributed to cause headache like head trauma, vascular disorder, substance abuse or withdrawal state, disorders of eye, ear, nose, sinuses and teeth were excluded from the study.

Ethical consideration: During the course of the study the privacy of the patient was maintained by taking interviews in a private and separate room, the patient's confidentiality was maintained with use of codes and an informed written consent was taken from the patient and spouse. Ethical approval was obtained from NMC Institution Review Committee (IRC)

The total number of patients $(n=75)$ were selected by simple random procedure with the patients that attended the outpatient department of NMCTH. Informed written consent was taken from the patient. At first a proforma was filled with the required information of the patient. Then a detailed history of the patient was taken including a detailed psychiatric history, any other medical or surgical history and history of substance abuse from the patient. Psychiatric morbidity was made according to ICD-10 with the help of General Health Questionnaire (GHQ), Self Reporting Questionnaire (SRQ) and Stressful Life Event scales (PSLES). Nepali/ Indian version of GHQ SRQ and PSLES was used..$^{20-}$ ${ }^{22}$ Finally, the data was analyzed using SPSS version 16 and simple descriptive statistics (percentage, mean and Standard Deviation) were analyzed. For association, Chi-square test was used, $p$ value of less than 0.05 was considered significant. 


\section{RESULTS}

Table 1: Socio-demographic Profile of Patient ( $n=75)$

\begin{tabular}{|c|c|c|}
\hline \multicolumn{2}{|c|}{ Variables } & \multirow{2}{*}{$\begin{array}{c}\text { Number (\%) } \\
10(13.4)\end{array}$} \\
\hline Age Range (years) & $16-20$ & \\
\hline & $21-25$ & $13(17.3)$ \\
\hline & $26-30$ & $20(26.7)$ \\
\hline & $31-35$ & $13(17.3)$ \\
\hline & $36-40$ & $6(8)$ \\
\hline & $41-45$ & $4(5.3)$ \\
\hline & $>45$ & $9(12)$ \\
\hline \multirow[t]{2}{*}{ Sex } & Male & $32(42.7)$ \\
\hline & Female & $43(57.3)$ \\
\hline \multirow[t]{2}{*}{ Marital Status } & Married & $52(69.3)$ \\
\hline & Unmarried & $23(30.7)$ \\
\hline \multirow[t]{6}{*}{ Employment Status } & Housewife & $22(29.3)$ \\
\hline & Service & $19(25.3)$ \\
\hline & Farmer & $12(16)$ \\
\hline & Business & $3(4)$ \\
\hline & Student & $16(21.4)$ \\
\hline & Unemployed & $3(4)$ \\
\hline \multirow[t]{6}{*}{ Literacy } & Illiterate & $15(20)$ \\
\hline & Primary & $12(16)$ \\
\hline & Secondary & $15(20)$ \\
\hline & SLC & $7(9.3)$ \\
\hline & Bachelors & $24(32)$ \\
\hline & Masters & $2(2.7)$ \\
\hline \multirow[t]{2}{*}{ Religion } & Hindu & $63(84)$ \\
\hline & Buddhist & $12(16)$ \\
\hline \multirow[t]{5}{*}{ Caste } & Brahmin & $29(38.7)$ \\
\hline & Chettri & $21(28)$ \\
\hline & Newar & $9(12)$ \\
\hline & $\begin{array}{c}\text { Gurung, Rai, Tamang, } \\
\text { Lama }\end{array}$ & $10(13.3)$ \\
\hline & Others & $6(8)$ \\
\hline
\end{tabular}

Table 2: Distribution according to different levels of Score

\begin{tabular}{lcr}
\hline \multicolumn{1}{c}{ Scoring system } & Scoring & Number (\%) \\
GHQ & $<16$ & $43(57.4)$ \\
& $16-20$ & $19(25.3)$ \\
\multirow{2}{*}{ SRQ } & $>20$ & $13(17.3)$ \\
& $\leq 10$ & $38(50.7)$ \\
PSLES & $>10$ & $37(49.3)$ \\
& $<150$ & $50(66.7)$ \\
& $150-199$ & $6(8)$ \\
& $200-299$ & $7(9.3)$ \\
\hline
\end{tabular}

As represented in table 1, most patients (26.7\%), who were studied upon were from the age group 26 to 30 years. Most were female $(57.3 \%)$ and $69.3 \%$ were married. A total of $29.3 \%$ of the patients were housewives followed by $25.3 \%$ patients who worked as service persons. $24 \%$ of the patients had studied up to bachelor's degree and they were mostly following Hinduism (84\%). A total of 38\% were Brahmins followed by $28 \%$ Chettris.

As seen in Table 2, $57.4 \%$ had GHQ scoring of $<16$ followed by $25.3 \%$ with $16-20$ and $17.3 \%$ with $>20$ scoring. $50.7 \%$ had SRQ scoring of $\leq 10$ and $49.3 \%$ had SRQ scoring of $>10$. $66.7 \%$ had PSLES scoring of $<150$ followed by $16 \%$ with $\geq 300$, 9.3\% with $200-299$ and $8 \%$ with $150-199$ scoring.

Table 3 : Distribution according to ICD-10 Diagnosis

\begin{tabular}{lc}
\hline ICD-10 diagnosis & Number (\%) \\
None & 57.3 \\
Anxiety Disorder & 21.3 \\
Depression & 17.4 \\
Somatization & 4 \\
Total & 100 \\
\hline
\end{tabular}

As shown in Table $3,57.3 \%$ of the patients had no ICD-10 diagnosis, $21.3 \%$ had anxiety disorder, $17.4 \%$ had Depression and $4 \%$ had Somatization.

Table no. 4: Distribution of ICD-10 diagnosis in relation to scores :

\begin{tabular}{llllll}
\hline $\begin{array}{l}\text { Scoring } \\
\text { System }\end{array}$ & Score & $\begin{array}{l}\text { Psychiatric Illness in } \\
\text { patient } \\
\text { Normal } \\
\mathbf{n}(\%)\end{array}$ & $\begin{array}{l}\text { Total } \\
\text { ICD-10 } \\
\text { Diagnosis } \\
\mathbf{n}(\%)\end{array}$ & p-value \\
GHQ & $\leq 15$ & $31(72)$ & $12(37.4)$ & $43(57.4)$ & 0.004434 \\
& $>15-20$ & $9(21)$ & $10(31.3)$ & $19(25.3)$ & \\
& $>20$ & $3(7)$ & $10(31.3)$ & $13(17.3)$ & \\
& Total & $43(100)$ & $32(100)$ & $75(100)$ & \\
SQR & $\leq 10$ & $31(72)$ & $7(21.9)$ & $38(50.7)$ & $<0.001$ \\
& $>10$ & $12(28)$ & $25(78.1)$ & $37(49.3)$ & \\
& Total & $43(100)$ & $32(100)$ & $75(100)$ & \\
\hline
\end{tabular}

As represented by Table 4, the p-value of distribution of ICD10 diagnosis in relation GHQ scoring and SQR scoring are 0.004434 and $<0.001$ respectively. Both of these values are $<0.05$ which indicates a significant value.

As shown in table 5, illness of family member and self or family member unemployment account for $12 \%$ each of the stressful life events in our patients followed by excessive alcohol or drug intake by a family member, pregnancy of wife/family members, death of close family member and financial loss or problem; which accounts for $9.3 \%$ each of stressful life events. 
Table no. 5 : Types of stress according to PSLES:

\begin{tabular}{|c|c|c|c|}
\hline Stressful Life Events & Male & Female & No. $(\%)$ \\
\hline Illness of Family Members & 1 & 8 & $9(12)$ \\
\hline $\begin{array}{l}\text { Excessive alcohol or drug use by } \\
\text { family members }\end{array}$ & 0 & 7 & $7(9.3)$ \\
\hline $\begin{array}{l}\text { Pregnancy of Wife/Family } \\
\text { members }\end{array}$ & 3 & 4 & $7(9.3)$ \\
\hline Suspension or dismissal from job & 1 & 0 & $1(1.3)$ \\
\hline Going to pleasure trip & 2 & 2 & $4(5.3)$ \\
\hline $\begin{array}{l}\text { Reduction in number of family } \\
\text { function }\end{array}$ & 2 & 4 & $6(8)$ \\
\hline Gain of new family members & 3 & 0 & $3(4)$ \\
\hline Begin or end of schooling & 3 & 0 & $3(4)$ \\
\hline $\begin{array}{l}\text { Detention in jail of self or close } \\
\text { family member }\end{array}$ & 0 & 1 & $1(1.3)$ \\
\hline Lack of child & 0 & 3 & $3(4)$ \\
\hline Death of close family member & 0 & 7 & $7(9.3)$ \\
\hline Death of a friend & 2 & 1 & $3(4)$ \\
\hline Financial loss or problem & 2 & 5 & $7(9.3)$ \\
\hline Sexual Difficulties & 0 & 1 & $1(1.3)$ \\
\hline $\begin{array}{l}\text { Self or family member unem- } \\
\text { ployed }\end{array}$ & 3 & 6 & $9(12)$ \\
\hline Outstanding achievement & 0 & 3 & $3(4)$ \\
\hline Change or expenses of business & 2 & 1 & $3(4)$ \\
\hline Unfulfillment of commitments & 1 & 2 & $3(4)$ \\
\hline Getting married or engaged & 1 & 0 & $1(1.3)$ \\
\hline $\begin{array}{l}\text { Appearing in examination or } \\
\text { interview }\end{array}$ & 3 & 0 & $3(4)$ \\
\hline Failure in exam & 2 & 2 & $4(5.3)$ \\
\hline Family conflict & 0 & 1 & $1(1.3)$ \\
\hline Marriage of daughter & 1 & 3 & $4(5.3)$ \\
\hline Large loan & 0 & 3 & $3(4)$ \\
\hline Trouble at work with colleagues & 0 & 1 & $1(1.3)$ \\
\hline Poverty or crops damaged & 2 & 4 & $6(8)$ \\
\hline
\end{tabular}

\section{DISCUSSION}

The study was conducted in Nepal Medical College Teaching Hospital in a study sample of 75 patients who visited Psychiatry OPD and who were diagnosed with Primary Headache. In this study, the majority of the patients were seen from the age group 26 to $30(26.7 \%)$ followed by the age group of 22 to 25 and 31 to 35 (each with 17.3\%). In a study done by Khalid et $\mathrm{al}^{23}$ headaches were more common in the age group 21 to 30 years (43.2\%) followed by 31-40 years $(20.43 \%)$. Another study done by Sharma, ${ }^{17}$ showed headache to be common in age group 21-25 (25\%) followed by $26-30(22.5 \%)$. A study done by Kafle et al $^{18}$ showed most patients were from age 20 to 39 years $(57.3 \%)$.

We also found out the predominant sufferers of Primary Headache were females (57.3\%). Studies done in TUTH by
Sharma ${ }^{17}$ showed $62.5 \%$ females and study done by Khalid et al. ${ }^{23}$ showed $61.92 \%$ female predominance. Study done by Kafle et al. ${ }^{18}$ showed $78.7 \%$ of the sufferers were female.

This study also showed the majority of the cases were married 69.3\%. In another study done by Khalid et $\mathrm{al}^{23}$ $68.73 \%$ of patients were married and $30.65 \%$ unmarried. Study done by Sharma ${ }^{17}$ in contrast showed 65\% were unmarried. Koseoglu et al. ${ }^{24}$ did a study where $(24.3 \%)$ of the cases were married followed by divorced people $(18.7 \%)$. Similarly, study done by Kafle et al. ${ }^{18}$ showed $89.3 \%$ of the patients were married.

It was also observed in our study that most of the patients were educated up to Bachelor's level (32\%) followed by secondary school level (20\%). The least number of participants had a Master's level of education $(2.7 \%)$. Koseoglu et al. ${ }^{24}$ did a study where he found chronic type headache to be most prevalent in the lowest education level (26.5\%). Another study done by Sharma ${ }^{17}$, in patients with Tension Type headache, majority (32.5\%) have passed matriculation exam, followed by those in intermediate level. Also study done by Kafle et al. ${ }^{18}$ showed $34.7 \%$ of the people with secondary level education status which was the maimum number followed by primary school level (23.3\%).

Majority of the cases in this study were housewives $(29.3 \%)$ followed by service holders (25.3\%) and least were unemployed (4\%). Study done by $\mathrm{Kafle}^{18}$ showed $56.7 \%$ of the patients worked as homemakers followed by $12 \%$ farmers. Koseoglu et al. ${ }^{34}$ did a study where he found that tension type headache was more prevalent in housewives than working women. Another study by Sharma ${ }^{17}$ showed the majority of the patients were students (40\%) which also included married women who were still studying.

This study also showed $84 \%$ were Hindu and the rest were Buddhist. This data is mainly due to population demography of Nepal which constitutes $80.6 \%$ Hindus and $10.7 \%$ Buddhists of total population. $38.7 \%$ of the patients in this study were Brahmins followed by $28 \%$ Chettri. This data is also due to the predominance of those castes in our country. Among the 75 patients, ICD-10 criteria was used to diagnose psychiatric conditions among which it was found that $57.3 \%$ had no psychiatric diagnosis. But, among those 75 patients $42.7 \%$ had some form of psychiatric diagnosis and anxiety (50\%), depression (40.6\%) and somatization (9.4\%) were the most common co-morbid conditions.

This study shows that among the 32 patients with some form of psychiatric illness, 16 were suffering from anxiety disorder, 13 from Depression and 3 from Somatization. A study done by $\mathrm{Kafle}^{18}$ showed that Anxiety was the most common co- 
morbid condition which was reported to be $31.3 \%$ followed by Depression (22\%). Another study done by Beghi et al. ${ }^{11}$ anxiety, mostly generalized type was reported by $9.3 \%$ of patients with tension type headaches and depressive episodes in $36.4 \%$ patients. Another study by Risal ${ }^{16}$ also showed that having any headache was significantly associated with Anxiety (17.2\%) compared to no headache (10.5\%) but the study could not find any significant association between having headache and depression cases.

In this study, it was found that the major Stressful Life Event was illness of family members (12\%) followed by excessive alcohol or drug use by a family member and death of close family members $\left(9.3 \%\right.$ each). A study done by Sharma ${ }^{17}$ showed marriage and failure in exams were the main stresses.

\section{CONCLUSION}

Prevalence of psychiatric morbidity has been seen in patients with Primary Headache. Majority was seen in females and of the age group 26 to 30 years. Major co-morbidities seen were anxiety, followed by depression and somatization. Illness of family members was found to be one of the main stressful life events followed by alcohol use among males which was found to be a major stressful event in the corresponding females who may be the wife or mother. There was also a significant relation between the distribution of ICD-10 diagnosis with the GHQ and SQR scores. Thus, we can conclude that psychiatric morbidities can be seen in patients with primary headache in a low age group as low as 16 to 20 years old. So, it is necessary to screen patients at an early age to improve the quality of life in patients as well as improve the overall living standards. Married females are at greater risk of these morbidities and education level also seems to add to the risk. Need of higher education should thus be promoted and people should be made aware of the disease they are suffering from as well as the prognosis of it. Regular psychiatric evaluation must be done in these patients and early diagnosis and appropriate interventions should be done as early as possible.

\section{LIMITATIONS}

The sample size was small which is the major limitation of the study. The study sample is also only taken from the OPD so it might not represent the population of our country with other ethnic groups.

\section{CONFLICT OF INTEREST}

None declared.

\section{FUNDING}

No any funding source.

\section{REFERENCES}

1. Magiorkinis E, Diamantis A, Mitsikostas DD, Androutsos G: Headaches in antiquity and during the early scientific era. J Neurol. 2009;256:1215-20.

2. Vos T, Flaxman AD, Naghavi M, Lozano R, Michaud C, Ezzati M, et al. Years lived with disability (YLDs) for 1160 sequelae of 289 diseases and injuries 1990-2010: A systematic analysis for the Global Burden of Disease Study 2010. Lancet. 2013;380:2163-96.

3. Lipchik GL, Penzien DB. Psychiatric comorbidities in patients with headaches. Semin Pain Med 2004;2:93105.

4. Lake AE, Rains JC, Penzien DB, Lipchik GL. Headache and psychiatric comorbidity: historical Context, clinical implications, and research relevance. Headache. 2005;45:493-506.

5. Pompili M, Serafini G, Di Cosimo D, Dominici G, Innamorati $\mathrm{M}$, Lester $\mathrm{D}$, et al. Psychiatric comorbidity and suicide risk in patients with chronic migraine. Neuropsychiatr Dis Treat. 2010;6:81-91. DOI: 10.2147/ NDT.S8467

6. Merikangas KR, Angst J, Isler $\mathrm{H}$. Migraine and psychopathology. Results of the Zürich cohort study of young adults. Arch Gen Psychiatry. 1990;47(9):849-53. DOI: 10.1001/archpsyc.1990.01810210057008.

7. Breslau N, Davis GC. Migraine, physical health and psychiatric disorder: a prospective epidemiologic study in young adults. J Psychiatr Res. 1993;27(2):211-21. DOI: 10.1016/0022-3956(93)90009-Q

8. Baskin SM, Smitherman TA. Migraine and psychiatric disorders: comorbidities, mechanisms, and clinical applications. Neurol Sci. 2009;30(Suppl 1):S61-S65. DOI: $10.1007 / \mathrm{s} 10072-009-0071-5$

9. Boye B, Lundin KE, Leganger S, Mokleby K, Jantschek G, Jantschek I, et al. The INSPIRE study: do personality traits predict general quality of life (Short form-36) in distressed patients with ulcerative colitis and Crohn's disease? Scand J Gastroenterol. 2008;43(12):1505-13. DOI: $10.1080 / 00365520802321196$

10. Lanteri-Minet M, Radat F, Chautard MH, Lucas C. Anxiety and depression associated with migraine: influence on migraine subjects' disability and quality of life, and acute migraine management. Pain. 2005;118(3):319- 
26. DOI:10.1016/j.pain.2005.09.010

11. Beghi E, Allais G, Cortelli P, D'Amico D, De Simone R, d'Onofrio $F$, et al. Headache and anxiety-depressive disorder comorbidity: the HADAS study. Neurol Sci. 2007;28(Suppl 2):S217-S219. DOI: 10.1007/s10072007-0780-6

12. Puca F. Psychological and social stressors and psychiatric comorbidity in patients with migraine without aura from headache centers in Italy: A comparison with tensiontype headache patients. J Headache Pain. 2000;1:17-25.

13. Puca F, Guazzelli M, Sciruicchio V, Libro G, Sarchielli P, Russo S, et al. Psychiatric disorders in chronic daily headache: Detection by means of the SCID interview. J Headache Pain. 2000;1:Suppl: 33-7.

14. Mongini F, Rota E, Deregibus A, Ferrero L, Migliaretti G, Cavallo F, et al. Accompanying symptoms and psychiatric comorbidity in migraine and tension-type headache patients. J Psychosom Res. 2006;61:447-51.

15. Perozzo P, Savi L, Castelli L, Valfrè W, Lo Giudice R, Gentile $S$, et al. Anger and emotional distress in patients with migraine and tension-type headache. J Headache Pain. 2005 Oct;6(5):392-9. DOI: 10.1007/s10194-0050240-8 PMID: 16362712.

16. Risal A, Manandhar K, Holen A, Steiner TJ, Linde M. Comorbidities of psychiatric and headache disorders in Nepal: implications from a nationwide population based study. The journal of Headache and Pain. 2016;17:45. DOI 10.1186/s10194-016-0635-8.
17. Sharma VD. Headache, a prospective study. J Institute of Medicine. 1998;20:46-53.

18. Kafle B, BagaleY ,Dhungana M. Anxiety and Depression as Co-morbidities in Patients with Primary Headache. Journal of Psychiatrists' Association of Nepal. 2018;6:459. DOI: $10.3126 /$ jpan.v6i2.21760

19. Olesen J, Bes A, Kunkel R, Lance JW, Nappi G, Pfaffenrath V, et al. Cephalalgia. 2018;38(1):1-21.

20. Koirala NR, Regmi SK, Sharma VD. Sensitivity and Validity of the General Health Questionnaire-12 (GHQ12 ) in the rural community system, in Nepal. Nepalese J Psychiatr. 1999;1:34-40.

21. Wright C, Nepal MK, Bruce-Jones WD. Mental health patients in primary health care services in Nepal. Asia Pac J Public Health. 1989;3(3):224-30. DOI: 10.1177/101053958900300309 PMID: 2620024.

22. Singh G, Kaur D, Kaur H. Presumptive stressful life events scale (psles) - a new stressful life events scale for use in India. Indian J Psychiatry. 1984 Apr;26(2):107-14. PMID: 21965968.

23. Regmi SK, Khalid A, Nepal MK. A study of sociodemographic characteristics and diagnostic profile in psychiatric outpatients of TUTH. Nepalese Journal of Psychiatry. 1999;1(1):26-33.

24. Köseoglu E, Naçar M, Talaslioglu A, Cetinkaya F. Epidemiological and clinical characteristics of migraine and tension type headache in 1146 females in Kayseri, Turkey. Cephalalgia. 2003 Jun;23(5):381-8. DOI: 10.1046/j.1468-2982.2003.00533.x PMID: 12780769. 